\title{
PENCIPTAAN SELENDANG BATIK SRI KUNCORO KHAS BUDAYA SAMIN MARGOMULYO BOJONEGORO
}

\author{
Sugeng Wardoyo ${ }^{1}$, Tri Wulandari ${ }^{2}$, Guntur $^{3}$, Dharsono ${ }^{4}$, Zulkarnain ${ }^{5}$ \\ Jurusa Kriya Fakultas Seni Rupa Institut Seni Indonesia Yogyakarta ${ }^{\text {Idan } 2}$ \\ Institut Seni Indonesia Yogakarta \\ Jl. Parangtritis Km 6.5 Sewon, Bantul, Kode Pos 55001 \\ Yogyakarta. Indonesia \\ Pascasarjana Institut Seni Indonesia Surakarta ${ }^{3,4, \text { dan } 5}$ \\ Institut Seni Indonesia Surakarta \\ Jl. Ki Hajar Dewantara No. 19, Jebres, Kec. Jebres, Kota Surakarta, Kode Pos 57126 \\ Jawa Tengah. Indonesia \\ Email: sgngwardoyo@gmail.com,tri.wulandari@isi.ac.id, gunturisi@yahoo.co.id, \\ eyangdharso@gmail.com,zoelmis@gmail.com
}

\begin{abstract}
Abstrak
Fokus penciptaan ini adalah merancang motif batik untuk selendang khas masyarakat Samin Margomulyo Bojonegoro dengan sumber inspirasi dari ajaran luhur Samin Surosentiko. Selama ini belum ditemukan artefak selendang dengan ciri khas motif batik masyarakat Samin Margomulyo. Metode yang digunakan adalah metode penciptaan practice based research dan dikombinasi dengan metode penciptaan seni. Tujuan penciptaan ini adalah merancang, menciptakan, dan mewujudkan selendang dengan motif batik Sri Kuncoro denagn mengeksplorasi budaya masyarakat Samin Margomulyo Bojonegoro. Tahapan penelitian ini diawali dengan pengumpulan data, analisis data, dan penyajian hasil analisis. Hasil analisis akan dipergunakan untuk bahan perancangan produk, dimulai dari pra perancangan, perancangan, perwujudan, dan penyajian. Hasil penelitian ini berupa selendang batik Sri Kuncoro yang difungsikan sebagai pelengkap dan identitas busana masyarakat Samin Margomulyo. Motif batik Sri Kuncoro memiliki arti sebuah pengharapan bagi pengantin untuk mendapatkan kecukupan rejeki yang halal dan kebahagiaan serta ketentraman batin dalam membina kehidupan rumah tangga.
\end{abstract}

Kata Kunci: selendang, batik, budaya, samin margomulyo.

\begin{abstract}
The focus of this creation is to design batik motifs for the distinctive scarves of the Samin Margomulyo Bojonegoro community with a source of inspiration from the noble teachings of Samin Surosentiko. So far, there have been no scarf artefacts with the characteristic batik motif of the Samin Margomulyo community. The method used is the method of creating practice-based research and combined with art creation methods. . This creation aims to design, create, and realize a scraves with Sri Kuncoro batik motifs to explore the culture of the people of Samin Margomulyo Bojonegoro. This stage of research begins with data collection, data analysis, and the presentation of analytical results. The analysis results will be used for product design materials, starting from pre-design, design, embodiment, and presentation. The results of this study in the form of Sri Kuncoro batik scarves functioned as a complement and identity of people's clothing Samin Margomulyo. The Sri Kuncoro batik motif means a hope for the bride and groom to get adequacy of halal windfall and happiness and inner peace in fostering home life.
\end{abstract}

Keywords: scarves, batik, culture, samin margomulyo.

\section{PENDAHULUAN}

Keterbukaan suku Samin dengan masyarakat sangat terlihat jelas sejak tahun 2000 hingga saat ini. Hal ini disebabkan adanya peningkatan intensitas mereka dalam berinteraksi dengan masyarakat luas, sehingga terjadi transformasi atau perubahan sosial dalam masyarakat Samin di Bojonegoro, baik dari aspek ilmu pengetahuan dan teknologi, agama dan sistem kepercayaan maupun tradisi atau adat istiadat (Hanifah, 2019: 44). Sifat positif bagi orang Samin yang mau menerima pandangan dari luar, berpengaruh pada pola pikir dan gaya hidup akan berkembang, sedangkan masyarakat akan terpengaruh oleh sifat kejujuran atau kekhasan lainnya dari karakter masyarakat Samin (Huda \& Wibowo, 2013: 145). Masyarakat Samin telah menunjukkan perubahan dan keterbukaan penerimaan 
dalam aspek, teknologi, agama, pola pikir, hingga gaya hidup.

Adanya faktor pengaruh informasi dari orang luar masyarakat Samin telah menyamarkan kehidupan perempuan Samin generasi saat ini telah menjadi seperti masyarakat biasa, namun sistem ajaran patriarki tidak ditinggalkan (Huda, 2020: 88). Perempuan Samin sebagai bagian dari masyarakat memiliki peran dalam mempertahankan nilai ajaran dari leluhurnya. Perempuan Samin sebagai pewaris tradisi menjadi bagian dalam kelangsungsan dan keberlangsungan eksistensi tradisi dari masa ke masa.

Busana perempuan masyarakat Samin Margomulyo Bojonegoro memiliki kekhasnya pada penggunaan selendang sebagai pelengkap berbusana. Selama ini belum ditemukan selendang dengan ciri khas motif batik masyarakat Samin Margomulyo. Masyarakat Samin Margomulyo berkeinginan untuk tetap menjaga dan melestarikan esensi ajaran luhurnya. Dalam hal ini terkait dengan fungsi selendang digunakan untuk acara ritual adat Samin. Salah satunya digunakan untuk acara ritual adat pernikahan masyarakat Samin margomulyo Bojonegoro.

Fokus pada penelitian ini adalah merancang motif batik untuk selendang khas masyarakat Samin Margomulyo Bojonegoro dengan terinspirasi dari esensi ajaran luhur Samin Surosentiko. Melalui bentuk visualisasi bunga Cempaka Mulya sebagai metafor yang mewakili motif utama, dan dikombinasi bentuk imajinatif. Motif-motif batik inilah dapat dijadikan simbol artefak sebagai kekayaan budaya masyarakat Samin Margomulyo dan dikembangkan serta dilestarikan sesuai dengan perkembangan zaman.

Permasalahan pada penelitian ini adalah: 1) Bagaimana proses eksplorasi ciri khas motif batik masyarakat Samin Margomulyo?; 2) Bagaimana proses dan hasil perwujudan karya batik tulis yang berupa selendang dengan ciri khas motif masyarakat Samin Margomulyo; 3) Apa makna motif ciri khas masyarakat Samin Margomulyo?

Tujuan penelitian ini yaitu untuk melestarikan ajaran luhur Samin Surosentiko yang selama ini diajarkan melalui lisan, kemudian divisualkan dengan media selendang sebagai artefak karya seni. Fenomena ini penting untuk dikaji karena harapan ke depan akan menjadi motif khas masayarakat Samin Margomulyo Bojonegoro, sekaligus dapat menjadi salah satu identitas pelengkap busana adat, serta dapat dipatenkan.

\section{KAJIAN TEORI}

Samin Bojonegoro dan Dunia (Prayudi, 2017), Dinas Kebudayaan dan Pariwisata Bobonegoro. Buku ini menjelaskan sosok Samin Surosentiko, nilai luhur ajaran Samin, tantangan adopsi nilai dalam kehidupan, cerminan harapan dan cita-cita masa depan dan Samin dan Bojonegoro meniti peradaban.

Etnografi Masyarakat Samin di Bojonegoro: Potret Masyarakat Samin Dalam Memaknai Hidup (Munawaroh et al., 2015). Buku ini menjelaskan tentang inti ajaran hidup masyrakat Samin didasarkan pada 3 hukum/aturan yaitu angger-angger pengucap, angger-engger perilaku, dan angger-angger lakunana. Transformasi Sosial Masyarakat Samin di Bojonegoro: Analisis Perubahan Sosial dalam Pembagian Kerja dan Solidaritas Sosial Emile Durkheim (Hanifah, 2019), Jurnal Sosiologi Agama, Universitas Islam Negeri Sunan Ampel Surabaya. Jurnal ini menjelaskan tentang memahami sekaligus menafsirkan makna fenomena perilaku masyarakat Samin Bojonegoro.

Motif Batik Untuk Udheng Masyarakat Samin Dusun Jepang Kabupaten Bojonegoro (Wardoyo, 2019), $3^{\text {rd }}$ International and Interdisciplinary Conference and Studies (IICACS 2019). Salah satu isi prosiding ini ialah tentang penciptaan motif batik untuk produk udheng khas masyarakat Samin Bojonegoro, dengan nama motif Obor Sewu.

Values and Characters of the Samin Society (Anfalia et al., 2020), International Conference on Educational Psychology and Pedagogy (ICEPP 2019). Penjelasan pada tujuan makalah ini adalah sebagai salah satu referensi tentang eksplorasi pendidikan karakter masyarakat Samin bersumber dari Sang pencipta, manusia dan lingkungan alam, yang dilestarikan dari generasi ke generasi berikutnya.

Perancangan Batik Dengan Inspirasi Cengkeh Dan Pace Untuk Selendang (Sari et al., 2019), Ornamen Jurnal Kriya vol. 16 no.01 Januari 2019. Salah pewarnaan yang digunakan dalam perancangan selendang yang terispirasi dari tanaman cengkeh dan pace ini menggunakan pewarna alami yaitu kulit kayu mahoni dan daun indigovera.

Batik Tulis Padang Lamun: Padang Lamun Sebagai Ide Perancangan Batik Tulis Untuk Selndang Sutra (Febrasari et al., 2018), Corak Jurnal Seni Kriya vol. 7 no. 2 Oktober 2018 - April 2019. Selendang batik tulis berbahan sutra crape dengan pewarnaan kimia, memvisualisasikan kesan bayangan atau ilusi yang menarik. 
Gorga : Jurnal Seni Rupa

Volume 10 Nomor 02 Juli-Desember 2021

p-ISSN: 2301-5942 | e-ISSN: 2580-2380

\section{METODE PENELITIAN}

Penelitian ini adalah penelitian yang bersifat kualitatif, sehingga data yang diperoleh adalah data kualitatif. Metode pengambilan data melalui:

1. Observasi untuk menggali data dan mendokumentasikan aktivitas masyarakat Samin Bojonegoro.

2. Wawancara untuk mendapatkan informasi dari nara sumber dan tokoh adat setempat.

3. Penelusuran dokumen untuk menelusuri dan menggali sumber tertulis baik dari buku, jurnal, ensiklopedi, kamus, arsip, katalog, maupun foto/gambar.

Metode analisis data penelitian ini menggunakan analisis bibliometrik dengan VosViewer, kemudian dijelaskan secara diskriptif. Miles dan Hubermus telah menjelaskan bahwa ada tiga unsur penting dalam proses analisis penelitian kualitatif yaitu: reduksi data, penyajian data, dan verifikasi data (Miles \& Huberman, 1992: 18).

Metode penciptaan karya ini menggunakan metode Practice Based Research, merupakana metode penelitian yang dominan praktik, hal ini bertujuan untuk memperoleh pengetahuan baru melalui praktik dan hasil praktik sebagai outcomes. Praktik berbasis seni membutuhkan keahlian dan keterampilan dari peneliti. Melalui penelitian berbasis praktik seni sangat mendukung pengembangan keterampilan dan skill artistic seorang peneliti (Leavy, 2015: 206).

Metode penelitian seni rupa, kriya dan desain umumnya tidak ada teori tunggal sebab karakteristik seni rupa tergantung pada obyek dan subyek yang diangkat dalam penelitian (Hendyana, 2018:33). Salah satu metode yang digunakan dalam penelitian ini, dapat dijabarkan melaui prinsip dan alur sebagai berikut:

1. Pra-perancangan merupakan tahap eksplorasi data, ide gagasan, tema isu yang relevan, permasalahan yang terjadi di masyarakat. Pencarian tujuan dan bentuk visual melalui pengembaraan jiwa atau meditasi, pencarian data dilakukan dengan wawancara mendalam, studi pustaka dan observasi. Tujuan dan konsep dapat dimulai pada tahap ini.

2. Perancangan merupakan tahap deskripsi verbal dari hasil analisis fenomena yang ada, divisualkan dengan berbagai aspek. Gagasan visual dapat diwujudkan menjadi bentuk prototype dengan berbagai pertimbangan aspek bentuk, fungsi, nilai dan makna.
3. Perwujudan merupakan tahap merealisaikan visual model secara detail berdasarkan ukuran yang sesuai dengan nilai, fungsi dan makna. Pada tahap ini dibuat sketsa motif batik khas yang terinspirasi dari ajaran luhur Samin Surosentiko.

4. Penyajian merupakan tahap mengkomunikasikan dengan masyarakat, di sini terjadi dialog dan apresiasi dari masyarakat yang diharapkan dapat melengkapi guna penelitian berikutnya.

Dalam penelitan penciptaan seni tidak mutlak hanya satu metode saja, bahkan metode yang satu melengkapi metode yang lain. Metode penciptaan seni Dharsono Sony Kartika terdiri dari eksperimen, perenungan, pembentukan (Kartika, 2016: 51-54) yang dilakukan melalui beberapa tahapan:

\section{Eksperimen}

Eksperimen merupakan langkah kegiatan yang dilakukan pengkarya dalam melakukan langkah proses kreasi artistik/ penciptaan yang meliputi: a). Melakukan percobaan bahan alternatif yang sesuai denga ekspresi cipta seni yang dikehendaki; b). Melakukan percobaan beberapa teknik individu yang sesuai dengan ekspresi cipta seni yang diinginkan; c). Mencoba beberapa alternatif alat yang sesuai dengan ekspresi cipta yang dirancang; d). Pemilihan konsep visual/ tatasusun.

\section{Perenungan}

Langkah ini merupakan pengembaraan batin pengkarya dalam mencari simbol (metafora). Perenungan dilakukan untuk mencari serta menentukan simbolsimbol yang akan menjadi ikon dalam proses kreatif artistik dalam penciptaan karya seni. Simbol itu akan digunakan sebagai bahasa ekspresinya, dan kemudian akan digunakan sebagai motif pokok/ utama, motif pendukung dan motif isen-isen.

\section{Pembentukan}

Pembentukan merupakan rancangan tatasusun atau komposisi yang dirancang untuk mendapatkan bentuk atau struktur karya. Struktur merupakan komposisi yang akan selalu berkaitan dengan: a).Kualitas unsur sebagai ikon seni yang dirancang; b).Prinsip tatasusun (harmoni, kontras, irama, gradasi; c).Azas tatasusun meliputi keseimbangan dan kesatuan; d).Persiapan bahan, antara lain: katun primissima, beberapa pewarna kimia dan pewarna alam; e).Persiapan alat, antara lain: canting, wajan, kompor, gawangan, bak pewarnaan, kenceng tempat pelorodan; f).Teknik pembatikan menggunakan teknik batik tulis dengan pewarnaan 
Gorga : Jurnal Seni Rupa

Volume 10 Nomor 02 Juli-Desember 2021

p-ISSN: 2301-5942 | e-ISSN: 2580-2380

tutup celup; g). Tahap penyelesaian dengan menjahit sesuai pola selendang.

\section{HASIL DAN PEMBAHASAN}

1. Hasil

\section{1). Hasil Analisis Data}

Pengumpulan data literatur dari hasil penelitian sebelumnya berupa jurnal dan tesis. Pencarian data menggunakan database google scholar dengan kata kunci Samin, Budaya Samin, dan Selendang. Peneliti telah memilih beberapa hasil penelitian yang relevan untuk digunakan sebagai acuan dan perbandingan objek penelitian. Hasil penelusuran sumber didapatkan 21 judul penelitian dari rentang tahun 2009 - 2021.

Tabel 1. Hasil Penelitian Dalam Rentang Tahun 2009. 2021.

\begin{tabular}{|c|c|}
\hline Tahun & Judul Penelitian \\
\hline 2021 & $\begin{array}{l}\text { Perilaku Nasionalisme Masyarakat Di Era } \\
\text { Kemajuan Teknologi Dan Informasi Pada } \\
\text { Masyarakat Samin } \text { Di } \begin{array}{l}\text { Kabupaten } \\
\text { Bojonegoro }\end{array}\end{array}$ \\
\hline 2020 & $\begin{array}{l}\text { Ki Samin Surosentiko Dan Ajarannya } \\
\text { Dalam Tradisi Lisan Masyarakat Di } \\
\text { Kawasan Pegunungan Kendeng Provinsi } \\
\text { Jawa Tengah }\end{array}$ \\
\hline 2020 & $\begin{array}{l}\text { Peran Perempuan Samin dalam Budaya } \\
\text { Patriarki di Masyarakat Lokal Bojonegoro }\end{array}$ \\
\hline 2020 & $\begin{array}{l}\text { Eksistensi Tradisi Masyarakat Samin } \\
\text { Kabupaten Bojonegoro Pada Era Modern }\end{array}$ \\
\hline 2020 & $\begin{array}{l}\text { Kehidupan Sosial Ekonomi Masyarakat } \\
\text { Samin Kabupaten Bojonegoro dan } \\
\text { Potensinya Sebagai Sumber Belajar Sejarah } \\
\text { Lokal Pendahuluan }\end{array}$ \\
\hline 2020 & Values and Characters of the Samin Society \\
\hline 2019 & $\begin{array}{l}\text { Kebijakan Masyarakat Adat Samin Dalam } \\
\text { Pemilihan Kepala Daerah Perspektif Imam } \\
\text { Al-Mawardi: Studi Di Kec. Margomulyo } \\
\text { Kab. Bojonegoro }\end{array}$ \\
\hline 2019 & $\begin{array}{l}\text { Local / Global Disruption : The Response } \\
\text { of the Samin Movement to Modernity }\end{array}$ \\
\hline 2019 & $\begin{array}{l}\text { Transformasi Sosial Masyarakat Samin Di } \\
\text { Bojonegoro (Analisis Perubahan Sosial } \\
\text { dalam Pembagian Kerja dan Solidaritas } \\
\text { Sosial Emile Durkheim) }\end{array}$ \\
\hline 2019 & $\begin{array}{l}\text { Pemertahanan Identitas Karakter Budaya } \\
\text { Masyarakat Samin Di Desa Margomulyo } \\
\text { Bojonegoro }\end{array}$ \\
\hline 2019 & $\begin{array}{l}\text { Perancangan Batik Dengan Inspirasi } \\
\text { Cengkeh Dan Pace Untuk Selendang }\end{array}$ \\
\hline 2019 & $\begin{array}{l}\text { Motif Batik Untuk Udheng } \\
\text { Samin Dasyarakat } \\
\text { Bojonegoro }\end{array}$ \\
\hline 2018 & $\begin{array}{l}\text { Studi Etnobotani Tumbuhan Obat Pada } \\
\text { Masyarakat Suku Samin } \\
\text { Bojonegoro }\end{array}$ \\
\hline 2017 & $\mathrm{~Pa}$ \\
\hline
\end{tabular}

\begin{tabular}{|l|l|}
\hline 2017 & $\begin{array}{l}\text { Masyarakat Samin Ditinjau Dari Sejarah } \\
\text { Dan Nilai-Nilai Pendidikan Karakter }\end{array}$ \\
\hline 2014 & $\begin{array}{l}\text { Sosioantropologi Evolusi Simbol Ritual } \\
\text { Upacara Selamatan Sura Pada Masyarakat } \\
\text { Samin Jepang Margomulyo Bojonegoro } \\
\text { (Studi Kasus pada Masyarakat Terasing) }\end{array}$ \\
\hline 2014 & $\begin{array}{l}\text { Perubahan Sosial Kaum Perempuan Samin } \\
\text { Di Desa Klopoduwur Kecamatan Banjarejo } \\
\text { Kabupaten Blora Tahun 1995-2012 }\end{array}$ \\
\hline 2013 & $\begin{array}{l}\text { Spesifikasi Tata Rias Pengantin Wanita } \\
\text { Bojonegoro }\end{array}$ \\
\hline 2009 & $\begin{array}{l}\text { Interaksi Sosial Suku Samin Dengan } \\
\text { Masyarakat Sekitar (Studi Di Dusun Jepang } \\
\text { Desa Margomulyo Kecamatan } \\
\text { Margomulyo Kabupaten Bojonegoro) }\end{array}$ \\
\hline $\begin{array}{l}\text { Proses Transformasi Pertanian dan } \\
\text { Perubahan Sosial pada Masyarakat Samin } \\
\text { di Bojonegoro }\end{array}$ \\
\hline
\end{tabular}

Seluruh data hasil penelitian sebulumnya, kemudian analisis data bibliometik menggunakan VosViewer dengan fokus field pada abstrak dan kata kunci dalam bahasa inggris. Berikut hasil analisis data bibliometrik, ditemukan hubungan objek-objek penelitian sesuai kelas klaster masing-masing.

Tanda ikon lingkaran menunjukkan semakin besar ikon lingkaran berarti semakin besar objek tersebut menjadi bahan atau kajian dalam sebuah penelitian, misalnya seperti: samin, community, value, tradition, dan teaching. Tanda ikon lingkaran semakin kecil berarti bahwa objek tersebut masih sedikit menjadi bahan atau topik penelitian, contohnya: norm, role, samin culture, saminsm, attitude, marriage ceremony, dan motif. Hal ini dapat dicermati dalam diagram analisis klaster data pada Gambar 1.

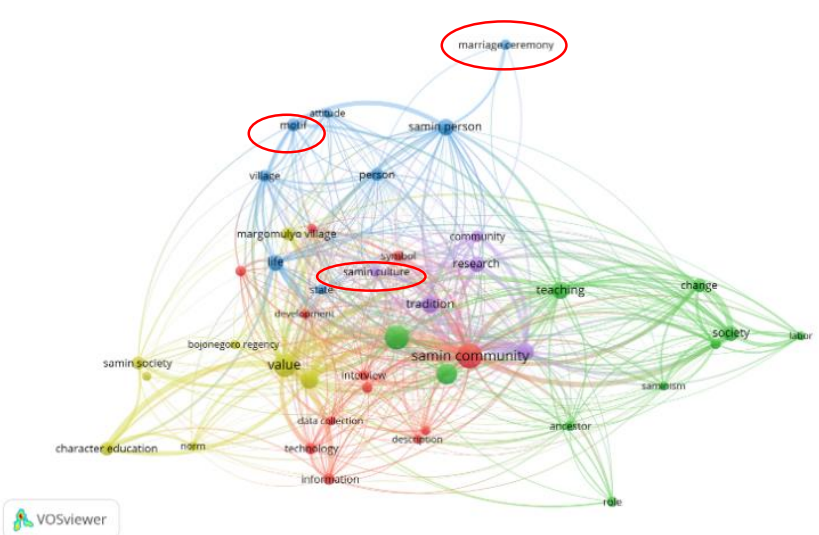

Gambar 1. Klaster Data Objek Penelitian.

Berdasarkan hasil klaster data objek penelitian, maka dalam penelitian ini memilih batasan objek penelitian yaitu hubungan antara budaya Samin (Samin culture), motif batik (motif), dan ritual adat pernikahan masyarakat Samin (ceremony marriage). Objek ini menjadi peluang objek penelitian karena masih sedikit 


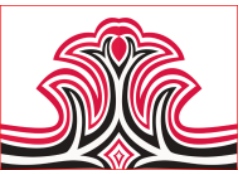

penelitian pada objek tersebut. Hal ini dikuatkan dengan beberapa ikon lingkaran kecil pada hasil analisis klaster objek-objek penelitian dalam rentang waktu 2009-2021.

Penelitian ini dilaksanakan pada tahun 2021 dengan tema penelitian penciptaan motif batik pada selendang yang difungsikan untuk pelengkap ritual adat pernikahan masyarakat Samin Bojonegoro. Lokasi penelitian tepatnya berada di Dusun Jepang, Desa Margomulyo, Kecamatan Margomulyo, Kabupaten Bojonegoro, Jawa Timur.

\section{2). Hasil Penciptaan Seni}

Hasil penciptaan motif batik dalam penelitian ini berupa motif Sri Kuncoro yang diaplikasikan pada produk selendang. Selendang sebagai pelengkap busana perempuan Samin. Selendang memiliki fungsi ritual dalam pernikahan Samin atau dalam kehidupan masyarakat Samin.

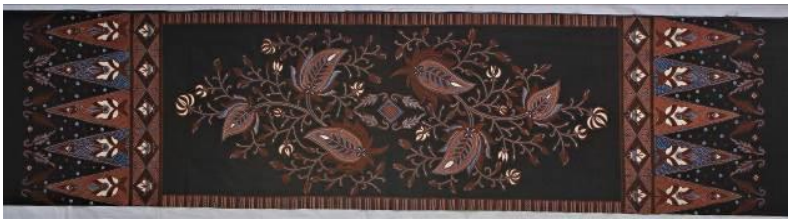

Gambar 2. Selendang Batik Sri Kuncoro.

Dalam karya selendang batik Sri Kuncoro terdiri dari motif utama bunga Cempaka Mulya, dikombinasikan dengan motif pendukung tumpeng dan obor. Motif Sri Kuncoro merupakan representasi dari nilai luhur yang ke tiga yaitu ojo mbedo mbedakne sapodo padaning urip, kabeh iku dedulure dewe yang artinya tidak membeda-bedakan sesama makhluk. Saling menghargai dalam kehidupan masyarakat akan tercipta kerukunan dan ketentraman.

\section{Pembahasan}

\section{1) . Proses Ekplorasi Motif Batik Sri Kuncoro}

Pada tahap pra-perancangan merupakan tahap eksplorasi data, ide gagasan, tema isu yang relevan, permasalahan yang terjadi di masyarakat. Penggalian eksplorasi ide pembuatan motif batik dari bunga Cempaka Mulya.
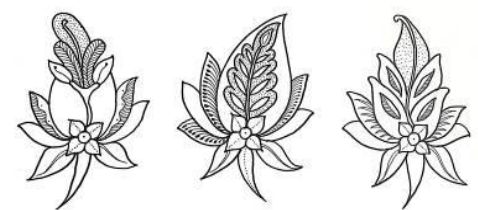

Gambar 3. Ragam Hias Bunga Cempaka Mulya.
Gorga : Jurnal Seni Rupa

Volume 10 Nomor 02 Juli-Desember 2021 p-ISSN: 2301-5942 | e-ISSN: 2580-2380

Perancangan merupakan tahap deskripsi verbal dari hasil analisis fenomena yang ada, divisualkan dengan berbagai aspek. Dalam perwujudan bentuk prototype desain motif batik didasarkan pada pertimbangan aspek bentuk, fungsi, nilai dan makna. Dari bentuk bunga Cempaka Mulya dijadikan dasar ide pembuatan desain motif batik Sri Kuncoro.

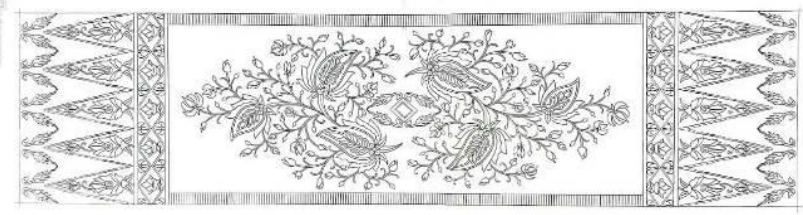

Gambar 4. Desain Motif Batik Sri Kuncoro.

\section{2).Proses dan Hasil Perwujudan Karya Selendang Batik Motif Sri Kuncoro}

Perwujudan merupakan tahap merealisaikan visual model secara detail berdasarkan ukuran yang sesuai dengan nilai, fungsi dan makna. Pada tahap ini dibuat sketsa motif batik khas yang terinspirasi dari ajaran luhur Samin Surosentiko.

\section{(1). Ngloyor atau Ngethel.}

Proses awal pembuatan batik tulis disebut dengan ngloyor atau ngethel yaitu proses pencucian kain dengan tujuan untuk membuka pori-pori serat kain sehingga mendapatkan daya serap warna yang lebih baik.

\section{(2). Nyorek atau Mola.}

Proses selanjutnya yaitu nyorek atau mola, merupakan proses menggambar motif dasar dan pola batik tulis diatas kain dengan menggunakan pensil sebagai dasar untuk membuat pola batik tulis. Namun beberapa motif tambahan sering dicorek langsung menggunakan canting diatas kain oleh pembatik yang sudah ahli.

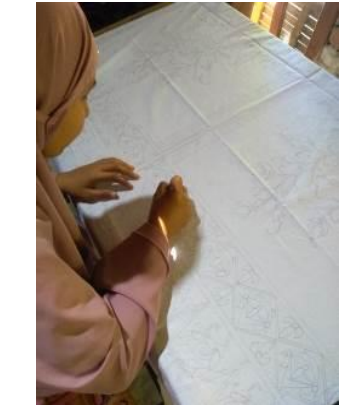

Gambar 5. Proses Nyorek atau Mola.

\section{(3). Nyanthing}

Proses pembuatan batik tulis selanjutnya adalah nyanthing. Proses nyanthing atau sering disebut dengan membatik ini merupakan proses yang membutuhkan tingkat kesabaran dan ketelitian yang tinggi. 

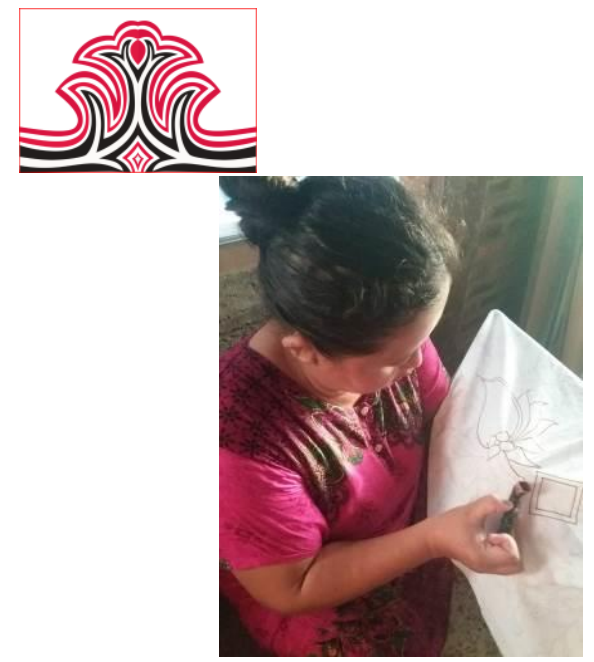

Gambar 6. Proses Nyanthing.

Proses nyanthing menggunakan lilin panas dengan menggunakan canting untuk membuat outline (nglowongi), dilanjutkan mengeblok pada bagian yang lebar atau luas (nemboki), dan diakhiri dengan pembuatan detil motif batik tulis (ngisen-iseni).

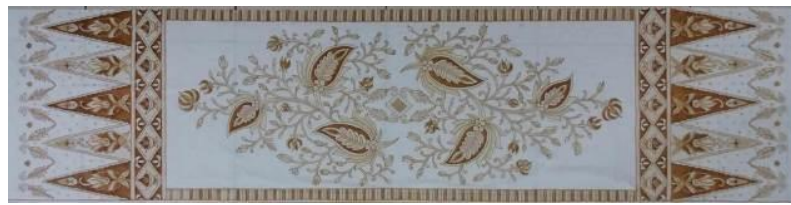

Gambar 7. Hasil Kain Batik Proses Nyanthing.

\section{(4). Medel}

Proses pembuatan batik tulis berikutnya adalah medel, yaitu proses mencelup kain batik tulis yang sudah dibatik dengan lilin (malam) ke dalam cairan pewarna pertama. Proses pembuatan batik tulis pada tahap pencelupan dilakukan tiga kali pengulangan hingga mendapatkan warna yang diinginkan.

Campuran warna wedel yang digunakan yaitu:

Naptol ASBO 100 gram

ASLB 25 gram

Kostik 35 gram

TRO 2 gram

Garam Biru B 150 gram, Hitam B 35 gram

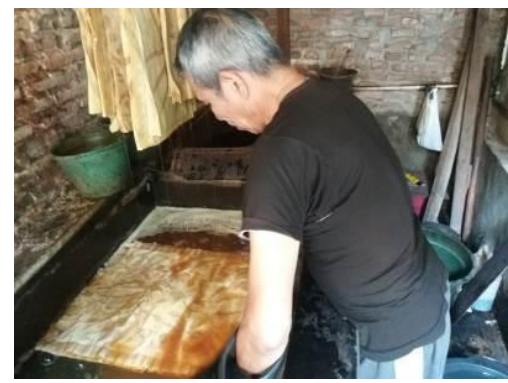

Gambar 8. Proses Pewarnaan Medel.

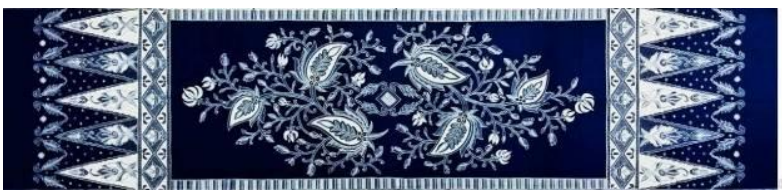

Gambar 9. Hasil Pewarnaan Medel.
Gorga : Jurnal Seni Rupa

Volume 10 Nomor 02 Juli-Desember 2021 p-ISSN: 2301-5942 | e-ISSN: 2580-2380

\section{(5). Mbironi}

Proses mbironi bertujuan untuk menutupi detail-detail corak batik tulis dengan lilin panas menggunakan canting. Proses ini juga bertujuan untuk melengkapi motif batik yang ingin dicapai, seperti menentukan bagian warna biru yang diinginkan. Ada kombinasi teknik ngisen-iseni yaitu dengan membuat ragam isenisen titik yang saling berderetan secara teratur sehingga disebut dengan proses ngrining.

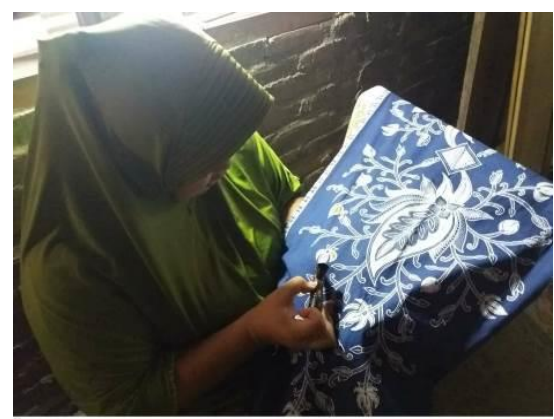

Gambar 10. Proses Mbironi.

\section{(6). Nyoga}

Proses nyoga adalah proses pewarnaan yang pada dasarnya sama seperti proses medel pada tahap sebelumnya, namun pada proses ini dilakukan untuk menambahkan warna lain pada kain batik tulis yang sudah diberi warna sebelumnya.

Campuran warna soga yang digunakan yaitu:

Naptol ASG 50 gram

ASLB 30 gram

Soga 9130 gram

Kostik 30 gram

TRO 2 gram

Garam Biru B 50 gram, 3 GL 50 gram, GG 50 gram.

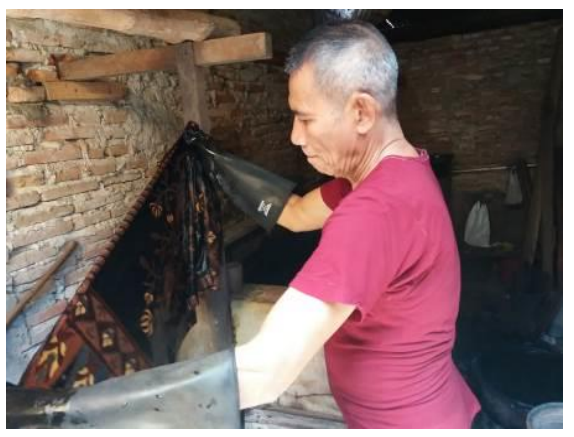

Gambar 11. Proses Nyoga.

\section{(7). Nglorod dan Penjemuran}

Proses nglorod adalah proses perebusan kain yang sudah dibatik ke dalam air panas. Hal ini bertujuan untuk menghilangkan lilin dari kain. Setelah itu kain batik tulis dibilas dengan air bersih dan terakhir dijemur atau dikeringkan dengan cara diangin-anginkan di tempat yang teduh. 


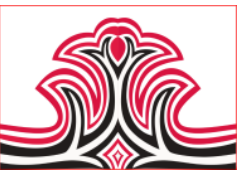

Batik yaitu kain yang ragam hiasnya ditulis dengan menggunakan malam sebagai perintangan warna, sehingga zat warna tidak dapat masuk ke dalam bagian kain yang tertutup malam saatpencelupan warna. Dalam proses membubuhkan malam di atas kain, maka digunakan canting sebagai alat menuliskan lilin malam. Bentuk kecil seperti mangkuk berujung pipa kecil berbahan tembaga, yang diberi gagang pegangan dari bahan kayu atau bambu (Ishwara et al., 2011: 23).

Pada tahap penyajian merupakan tahap mengkomunikasikan produk batik dengan masyarakat, di sini terjadi dialog dan apresiasi dari masyarakat yang diharapkan dapat melengkapi guna penelitian berikutnya. Penyajian produk batik dapat dilakukan dengan cara packajing dan display produk yang menarik. Batik merupakan produk budaya yang telah menjadi bagian ekonomi kreatif di Indonesia. (Wulandari, 2021: 166).

\section{3). Makna Motif Sri Kuncoro}

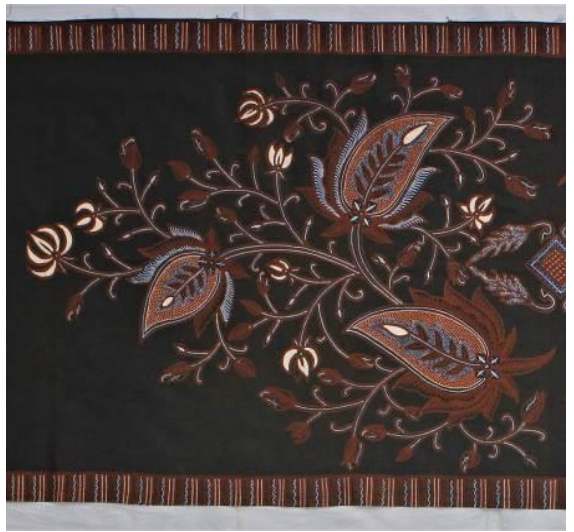

Gambar 12. Detail Motif Sri Kuncoro

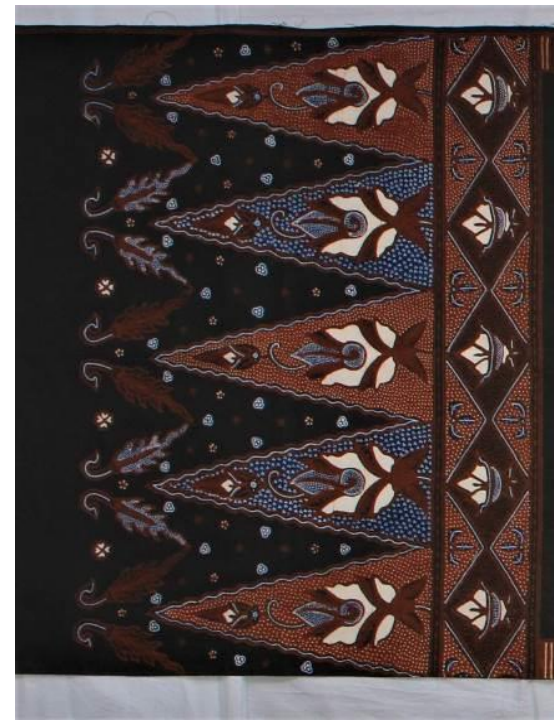

Gambar 13. Detail Motif Cempaka Mulyo pada Bagian Tumpal.
Gorga : Jurnal Seni Rupa

Volume 10 Nomor 02 Juli-Desember 2021 p-ISSN: 2301-5942 | e-ISSN: 2580-2380

"Sri”" dalam bahasa Jawa memiliki arti dan makna ratu, selamat, berkah, rejeki, dan "Kuncoro" memiliki makna kebahagiaan, harapan. Dalam hal ini, terdapat sebuah harapan bagi pengantin untuk mendapatkan kecukupan rejeki yang halal dan kebahagiaan serta ketentraman batin dalam membina kehidupan rumah tangga. Selendang batik Sri Kuncoro ini dikenakan oleh perempuan Samin sebagai pelengkap busana.

Penciptaan perubahan suatu motif memiliki pertimbangan dengan apa digemari oleh penggunanya, yaitu motif cenderung sederhana tanpa corak yang berlebihan, sehingga tidak mengganggu keindahan pakaian secara keseluruhan (Delila \& Wiratma, 2017: 98). Oleh karena itu, penciptaan motif batik Sri Kuncoro ini telah mempertimbangkan aspek makna, fungsi, dan kegunaannya. Keindahan motif dipertimbangkan dengan keselarasan busana masyarakat Samin. Pada akhirnya keindahan visual selendang batik Sri Kuncoro mendukungan keindahan berbusana perempuan Samin.

\section{KESIMPULAN DAN SARAN}

\section{Kesimpulan}

Hasil ide eksplorasi bunga Cempaka Mulya merupakan wujud representasi dari esensi nilai luhur yang ke tiga dari lima ajaran luhur Samin Surosentiko, yaitu ojo mbedo mbedakne sapodo padaning urip, kabeh iku dedulure dewe ( tidak membeda-bedakan sesama makhluk). Dari semula ajaran luhur bersifat lisan kemudian ditransformasikan dalam bahasa visual berupa selendang batik sebagai hasil utama penciptaan ini. Bunga cempaka mulya sebagai motif utama yang dikombinasikan visual tumpeng dan obor sebagai motif pendukung, divisualisasikan dengan pola simetris harmonis. Proses perwujudan menggunakan teknik batik tulis tutup celup dengan perwarnaan wedelan dan sogan, sehingga menghasilkan perpaduan warna dengan karakter khas klasik. Makna selendang batik motif Sri Kuncoro sangat erat dengan sebuah harapan dan doa dari pengantin Samin dalam membina kehidupan rumah tangga akan mendapatkan kebahagiaan serta kesejahteraan.

\section{Saran}

Dalam menumbuhkan upaya pelestarian ajaran luhur Samin Surosentiko melalui media visual selendang batik Sri Kuncoro ini diharapkan dapat digunakan sebagai wujud artefak karya seni. Adanya selendang batik Sri Kuncoro ini diharapkan dapat menjadi salah satu identitas pelengkap busana adat masyarakat Samin Margomulyo Bojonegoro, serta dapat dipatenkan. Dengan menggali kembali potensi - potensi budaya di komunitas Samin Margomulyo Bojonegoro, kemudian 


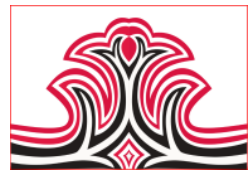

mengolah dengan media lain, dan mengembalikan pada adat budaya yang berlaku, akan semakin memperkuat serta dapat menopang keberlanjutan identitas budaya di masa depan. Saran ke depan untuk kajian penelitian, dapat terciptanya artefak karya seni lainnya yang dapat dikembangkan dari ajaran Samin Surorentiko.

\section{DAFTAR RUJUKAN}

Anfalia, R., Rachmawati, Y., \& Yulindrasari, H. (2020, February). Values and characters of the Samin society. In International Conference on Educational Psychology and Pedagogy-" Diversity in Education"(ICEPP 2019) (pp. 220223). Atlantis Press.

Delila, T., \& Wiratma, S. (2017). Kerajinan Batik Dan Perkembangany Studi Kasus Pada Ardhina Batik Medan. Gorga: Jurnal Seni Rupa, 6(2), 89. https://doi.org/10.24114/gr.v6i2.11026

Febrasari, A., Dartono, F. A., \& Santoso, R. E. (2018). Batik Tulis Padang Lamun (Padang Lamun Sebagai Sumber Ide Perancangan Batik Tulis Untuk Selendang Sutra). Corak, 7(2), 163-172. https://doi.org/10.24821/corak.v7i2.2683

Hanifah, U. (2019). Transformasi Sosial Masyarakat Samin Di Bojonegoro (Analisis Perubahan Sosial dalam Pembagian Kerja dan Solidaritas Sosial Emile Durkheim). Jurnal Sosiologi Agama: Jurnal Ilmiah Sosiologi Agama dan Perubahan Sosial, $\quad 13(1), \quad 41-74$ https://doi.org/http//dx.doi.org/10.14421/.

Hendriyana, Husen, (2018). Metodologi Penelitian Penciptaan Karya. Bandung: Sunan Ambu Press.

Huda, K. (2020). Peran Perempuan Samin dalam Budaya Patriarki di Masyarakat Lokal Bojonegoro. Sejarah dan Budaya: Jurnal Sejarah, Budaya, dan Pengajarannya, 14(1), 7690. https://doi.org/10.17977/um020v14i12020p76

Huda, K., \& Wibowo, A. M. (2013). Interaksi Sosial Suku Samin Dengan Masyarakat Sekitar (Studi Di Dusun Jepang Desa Margomulyo Kecamatan Margomulyo Kabupaten Bojonegoro). Jurnal Agastya, 3(1), 127-148.

Ishwara, H., L.R.Yahya, \& Moeis, X. (2011). Batik Pesisir Pusaka Indonesia, Koleksi Hartono Sumarsono. Jakarta: KPG Kepustakaan Populer Gramedia.

Kartika, Dharsono Sony. (2016). Kreasi Artistik, $L P K B N$. Solo: Citra Sains.

Leavy, P. (2015). Method Meets Art, Second Edition: Arts-Based Research Practice (Second). https://books.google.com/books?hl=en\&lr=\&id $=$ BOJdBgAAQBAJ\&pgis=1 (diakses tanggal 01 Januari 2020).

Miles, M. B., \& Huberman, A. M. (1992). Analisis Data Kualitatif: Buku Sumber Tentang MetodeMetode Baru. Jakarta: UI Press.

Munawaroh, S., Ariyani, C., \& Suwarno. (2015). Etnografi Masyarakat Samin di Bojonegoro
Gorga : Jurnal Seni Rupa

Volume 10 Nomor 02 Juli-Desember 2021 p-ISSN: 2301-5942 | e-ISSN: 2580-2380

(Potret Masyarakat Samin Dalam Memaknai Hidup). Yogyakarta: Balai Pelestarian Nilai Budaya (BPNB) Yogyakarta.

Prayudi, Susilo, E., \& Prastiwi. D. (2017). Samin: Bojonegoro dan Dunia. Bojonegoro: Dinas Kebudayaan dan Pariwisata Bojonegoro.

Sari, P. C., H, S. R., \& S, R. E. (2019). Perancangan Batik Dengan Inspirasi Cengkeh Dan Pace Untuk Selendang. Ornamen Jurnal Kriya, 16(01), 1523.

Wardoyo, S. (2019). Motif Batik Untuk Udheng Masyarakat Samin Dusun Jepang Kabupaten Bojonegoro. 3rd International and Interdisciplinary Conference on Arts Creation and Studies (IICACS 2019), 3rd IICACS, 185199.

Wulandari, T. (2021). Eksistensi Batik Encim Dalam Arena Produksi Kultural Di Pekalongan. Gorga : Jurnal Seni Rupa, 10(1), 164. https://doi.org/10.24114/gr.v10i1.25255. 